\title{
Adaptation of Impulsive and Reflective Learning Behavior in a Game-Based Environment
}

\author{
Franziska Spring-Keller \\ University of Zurich, Department of Informatics, Educational Engineering \\ Lab, Switzerland, spring@ifi.uzh.ch
}

\begin{abstract}
This research deals with learning in digital environments. Adaptive game-based learning considers learners' preferred learning behavior and adapts the game system accordingly. In order to analyze learning behavior, the focus lies on a specific cognitive style, impulsive and reflective (I/R), which describe behaviors in problem-solving and decision-making environments. Impulsive people tend to react much faster than reflective ones but make more mistakes in their choices. Since impulsive behavior in learning is considered as rather weak behavior, this research of game-based learning environments wants to encourage impulsive learners and not particularly force a change in learning behavior. This approach is illustrated on the strategy and simulation game "Hortus".
\end{abstract}

\section{Introduction}

Every person has a different preference and approach of how to learn something new. Some people prefer to indulge in theoretical information while others rather like to learn from hands on experience.

There are also different research approaches to analyzing and supporting learner preferences. The analysis of these preferences is either based on a theoretical learner model or is implicitly collected (data mining) from user behavior during the use of a learning unit without a model from learning theory. Learner models mostly provide instructions of how to support a learner. Unfortunately, many studies of learning behavior are not based on recognized theories or could not deliver clear results of learning improvement $[1,2]$.

This paper focuses on a mixed approach that takes a specific learner attribute, cognitive style, and analyzes this behavior implicitly during the use of a learning unit. The cognitive style - impulsive and reflective - provides the most convenient conditions to implicitly analyze user behavior. 


\subsection{Cognitive style - impulsive and reflective (I/R)}

In problem-solving environments, there are a lot of situations where learners have to make decisions under great uncertainty. Some people rather solve few problems in order to avoid a high error rate. This group is defined as reflective. Other people rush over the whole situation and their goal is more to solve as many problems as possible in the given amount of time. These people are called impulsive [3]. Impulsive and reflective (I/R) behavior is measured using the so-called Matching Familiar Figures Test (MFFT) by Kagan et al. [4] and a revised and digitized version by Van Merrienboer and Jelsma [5].

In classic learning environments, impulsive learners are trained to re-think and change their behavior into a more reflective approach since the impulsive behavior is considered a weak behavior. This type of training is not the preferable and efficient way from the point of view of an impulsive learner. Therefore this trait will be investigated in greater detail in the game-based environment described below. Gamebased learning environments train problem-solving skills and most of the game designs tolerate "making mistakes". This crucial aspect is mostly not tolerated in classic learning environments [6].

\subsection{Learning in Games}

This research looks at a very particular kind of game-based learning environment. It includes simulation and strategy games such as Civilization or Sim City. These games are very popular and are often used for educational purposes [7, 8]. Students learn how to deal with restricted resources or experience historical events from an active perspective. Learning in these kinds of games is integrated into the game system and is not separated from the game context. Students learn by doing in a situated context [9]. The better they play the game, the better they understand the rules and the learning content, respectively. Information and background knowledge is provided on demand when players need it. These aspects support situated learning in the respective context.

Commercial games like Sim City are too complex and too big to use for learner analysis and adaptation. Therefore, in this research a separate game, "Hortus", is developed that is based on the same learning concept as Sim City or Civilization.

\section{An adaptive learning game to support I/R behavior}

\subsection{Analysis of I/R behavior}

Recent studies have used the MFFT or have transferred its dimensions to multiple choice systems [10]. This is much easier because there is a restricted amount of choices that can be either right or wrong. However, a choice does not necessarily have to be right or wrong according to the definition of $\mathrm{I} / \mathrm{R}$. In authentic problem- 
solving environments there is rarely a right and a wrong choice. In a game like Hortus, there are several possiblities of how to solve a problem. The game has five ascending goals. Each goal has vast possibilities of how to achieve them. However, the closer the player gets to the goal, the more countable the number of possible solutions becomes. There is a dynamic calculation and creation of a graph showing possible paths to the next sub-goal. Each single path is weighted depending on the quality of the choice.

The weights of each path are based on several criteria. For instance, one criterion is how economical players use their resources. Additional user behavior is collected to provide an accurate result for $\mathrm{I} / \mathrm{R}$. This is click frequency, time until a decision was made etc.

\subsection{Instructions for $\mathbf{I} / \mathbf{R}$}

Once the learners' profiles reveal whether they are impulsive or reflective, the game system reacts accordingly. This can occur on two levels: the information-based layer and content-based layer [11]. The first layer does not affect the game system. Instead, it mainly analyses past behavior, anticipates possible future steps or strategic decisions for the user. The other layer affects the game system.

For further research, content-based adaptation is of main interest. Changing some elements in a game system is much more challenging than changing the appearance of learning content in an e-learning unit. The goal is to create a personal learning experience for learners without changing the overall learning goal. An example would be adding or removing a resource in the game. By adding a single resource, the game could become strategically challenging for reflective learners who prefer to make strategies and plan ahead. Another possibility is to add more action elements for impulsive learners.

\section{Conclusion}

The state of the art in impulsive and reflective learning behavior is to measure it either with the Matching Familiar Figures Test (MFFT) or with multiple choice tasks. In this paper, a concept is introduced where $I / R$ is measured in an authentic environment with several possible solutions to a specific problem. A game-based environment provides this kind of environment. Since impulsive learners like to avoid direct questions because they are afraid to seem incompetent [12], a game for learning could help them by not getting them into this awkward situation.

Depending on the definition of an expert player/learner, impulsive people do not necessarily have to be forced into reflective behavior. Learning success might not only depend on how good and how fast someone solves a problem, but also on how someone deals with resources in the game or what kind of mistakes the player made. Therefore it has to be empirically tested if impulsive behavior has to be changed or can be enforced. The goal is to leave learners in their preferred area to the extent 
possible and not to force them to learn other styles that are preset by the designer or creator of the learning environment.

\section{References}

1.D.H. Jonassen and B.L. Grabowski, Handbook of Individual Differences in Learnin, and Instruction (Hillsdale, NJ: Lawrence Erlbaum Associates, 1993).

2.F. Coffield, D. Moseley, E. Hall and K. Ecclestone, Should we be using learning styles? What research has to say to practice. Learning and Skills Research Centre (London: Cromwell Press Ltd, 2004).

3.R.J. Sternberg, and L.-F. Zhang, Perspectives on Thinking, Learning, and Cognitive Styles (New Jersey: Lawrence Erlbaum Associates, 2001).

4.J. Kagan, B.L. Rosman, D. Day, J. Albert and W. Philips, (1964). Information processing in the child: Significance of analytic and reflective attitude. Psychological Monographs. Ed. 78, Vol. 1, Whole No. 578, 1964.

5.J.J.G. Van Merriënboer and O. Jelsma, The Matching Familiar Figure Test: Computer or Experimenter Controlled Administration. Educational and Psychological Measurement 48, pp. 161-164, 1988.

6. J.P. Gee, What Video Games Have To Teach Us About Learning And Literacy (Palgrave Macmillan, New York, 2003).

7. K.D. Squire, (2003) Video Games in Education. International Journal of Intelligent Simulations and Gaming, (2)1, pp. 49-62, 2003

8. K. Squire, Possibility spaces. In Katie Salen (Ed). The ecology of games. In the MacArthur Foundation Series on Digital Media Literacies (Chicago: MacArthur Foundation, in press).

9. J.P. Gee, What would a state-of-the-art instructional video game look like? Innovate 1 (6), (2005).

10. H.H. Mammar and F.T. Bernard, Incorporating cognitive styles into adaptive multimodal interfaces. CogSci, George Mason University, Fairfax, VA, August 8-10, 2002.

11. D. Burgos, C. Tattersall and R. Koper. Representing adaptive eLearning strategies in IMS Learning Design. Paper presented at the TENCompetence Conference, Sofia, Bulgaria, March 2006.

12. J. Kagan and N. Kogan, In Weiner, A.S. and Adams, W.V. (1974) The Effect of Failure and Frustration on Reflective and Impulsive Children. Journal of Experimental Child Psychology, 17, pp. 353-359, 1970. 